\title{
Construction of College English Blended Teaching Model: An Outcome-Based Education Approach
}

\author{
Lihua Wang \\ Department of College English, Zhejiang Yuexiu University, Shaoxing, China \\ Email: wanglihua1015@qq.com
}

How to cite this paper: Wang, L.H. (2021) Construction of College English Blended Teaching Model: An Outcome-Based Education Approach. Open Access Library Journal, 8: e7652.

https://doi.org/10.4236/oalib.1107652

Received: June 16, 2021

Accepted: September 25, 2021

Published: September 28, 2021

Copyright $\odot 2021$ by author(s) and Open Access Library Inc.

This work is licensed under the Creative Commons Attribution International License (CC BY 4.0).

http://creativecommons.org/licenses/by/4.0/

\begin{abstract}
Outcome-Based Education approach has attracted more attention for its concern on the needs of the society for talents and its emphasis on the curriculum construction from learning outcome. This paper researches on a four-step model in College English blended teaching process including defining, realizing, assessing, and using based on outcome-based education approach. With this closed-loop system, it adopts the outcome-oriented teaching model to construct a college English blended curriculum system that matches the expected English teaching objectives. The model is suggested to play an important role in the corresponding implementation plan.
\end{abstract}

\section{Subject Areas}

Language Education

\section{Keywords}

OBE Approach, College English, Blended Teaching

\section{Introduction}

With the integration of education and information technology, a blended teaching model began to emerge, which is normally defined as the integration of traditional classroom methods with online activities [1]. In recent years, blended teaching has become the focus of education reform in China. Guidelines on College English Teaching (2020) points out that colleges and universities should make full use of information technology to create a diversified teaching and learning environment. First-class undergraduate courses such as online courses, blended courses, and virtual simulation experiment courses need to be constructed to make 
students develop the habits of active learning, autonomous learning and personalized learning. For the past several years, blended teaching models have increased in large numbers in the English teaching process. Especially in 2020 affected by the epidemic, the development of large-scale online teaching accelerates the integration of information technology and English teaching reform, which not only ensures the classroom synchronous and online asynchronous meaningful communication, but also creates a cohesive learning experience and offer learners the advantage of flexibility in shifting time and space, among other benefits [2].

Although English blended teaching model can better the cultivation of students' abilities to a certain extent, the systematic design of the instructional objectives in blended teaching classrooms needs to be reconsidered, for it is always, like the traditional classroom teaching, designed in strict accordance with the prescribed teaching process and teaching contents, which could lead to unsuitability for learners' development needs and the impractical results they at last achieve. Moreover, although online course resources are classified and presented in abundance, they are designed by a knowledge system without the consideration from the perspective of teaching function and students' ability achievement. Therefore, the problems of how to plan systematic online courses and how to build courses suitable for learners' development needs have become urgent issues [3]. Meanwhile, as a general education course, College English also faces some criticism. One problem focuses on the fact that with more credits in English courses, the courses are actually not challenging but easy to pass. In students' view, they seem like "irrelevant" or "soft" courses. The other one is that the management forms adopted are faced with the difficulty of how to integrate with the other existing undergraduate curriculum and graduate goals to improve college students' English language competence [4]. Therefore, this paper uses the outcome-based education approach to carry out the reform and redesign of the College English blended teaching model. In combination with the background of the times and the status of colleges, it begins with putting forward the characteristic goal of College English General Education in China, and then carries out the construction of College English blended teaching model with an Outcome-Based education approach, which is expected to be useful in future practical fields.

\section{Construction of Teaching Model}

\subsection{OBE Approach}

Outcome-Based Education (OBE) first appeared in the primary education reform of the United States and Australia. From the 1980s to the early 1990s, it had been a popular term in American educational circle. In a book-Outcome-based Education: Critical Issues and Answers written by the American scholar Spady, OBE approach has been deeply studied. The book describes it as a theory clearly focusing on education system ensuring that students gain experience of substan- 
tial success in their future life [5]. It points out that OBE realizes the transformation of educational paradigm, since in OBE education mode, what students have learned and whether they are successful is far more important than how to learn and when to learn. Later, The Department of Education in Western Australia defines OBE as an educational process to realize students' specific learning outcome, as Tucker S.E. says that OBE is synonymous with Outcomes-Focused Education (OFE). Both OBE and OFE are a structure and system in which learning outcome drives the whole curriculum activities and students' learning evaluation [6]. Although opinions about OBE vary, there are obvious in commonalities (Table 1). In OBE approach, educators must have a clear idea of the ability that

Table 1. Review of different opinions in the evolution of OBE.

\begin{tabular}{|c|c|c|}
\hline Periods & Experts & Opinions about OBE \\
\hline \multirow{5}{*}{$\begin{array}{l}\text { The period } \\
\text { of advocacy }\end{array}$} & Tyler (1949). & $\begin{array}{l}\text { Determination of curriculum design by explicit } \\
\text { objectives expressed in terms of changes the learning } \\
\text { was supposed to produce in the behavior of students }\end{array}$ \\
\hline & Bloom (1956) & $\begin{array}{l}\text { Classification of a taxonomy of educational goals into } \\
\text { knowledge, skills, and attitudes, and stress of their } \\
\text { communicable abilities }\end{array}$ \\
\hline & Mager (1997) & Instructional objectives \\
\hline & Spady (1994) & $\begin{array}{l}\text { OBE as a process of clearly focusing and organizing } \\
\text { everything in an educational system around what is } \\
\text { essential for all students to be able to do successfully } \\
\text { at the end of their learning experiences }\end{array}$ \\
\hline & $\begin{array}{c}\text { Harden } \\
\text { et al. (1999) }\end{array}$ & $\begin{array}{l}\text { OBE as a performance-based approach at the cutting } \\
\text { edge of curriculum development (that) offers a powerful } \\
\text { and appealing way of reforming and managing medical } \\
\text { education }\end{array}$ \\
\hline \multirow{4}{*}{$\begin{array}{l}\text { The period of } \\
\text { implementation }\end{array}$} & Killen (2000) & $\begin{array}{l}\text { Formulation of OBE's three basic premises: all students } \\
\text { can learn and succeed, but not all at the same time or in } \\
\text { the same way; successful learning promotes even more } \\
\text { successful learning; schools (and teachers) control the } \\
\text { conditions that determine whether or not students are } \\
\text { successful at school learning }\end{array}$ \\
\hline & $\begin{array}{l}\text { Simpson } \\
\text { et al. }(2002) \text {. }\end{array}$ & $\begin{array}{l}\text { Possibility of meeting the first requirement of OBE, } \\
\text { to define learning outcomes }\end{array}$ \\
\hline & Tucker (2004) & $\begin{array}{l}\text { OBE as a process that should involve the restructuring } \\
\text { of curriculum, assessment, and reporting practices in } \\
\text { education }\end{array}$ \\
\hline & $\begin{array}{l}\text { Biggs \& Tang } \\
\quad(2009)\end{array}$ & $\begin{array}{l}\text { OBE educators striving for student achievement at a } \\
\text { level appropriate for each individual and the outcomes } \\
\text { specifically to enhance teaching and assessment, always } \\
\text { allowing for unintended but desirable outcomes }\end{array}$ \\
\hline \multirow{2}{*}{$\begin{array}{l}\text { The period of } \\
\text { recommendation }\end{array}$} & $\begin{array}{l}\text { Cooke } \\
\text { et al. }(2010)\end{array}$ & $\begin{array}{l}\text { Recommendation of widespread adoption of OBE } \\
\text { and clear, progressive expectations of learners }\end{array}$ \\
\hline & Hodges (2010) & $\begin{array}{l}\text { Standardization of learning outcomes based on a } \\
\text { "production discourse" }\end{array}$ \\
\hline
\end{tabular}


students should achieve when they graduate, and then seek to design an appropriate education structure to ensure that students achieve these expected goals. Students' outcomes rather than textbooks or teacher experiences have been a driving force for the operation of the educational system. This is clearly in contrast to the traditional content-driven or input-oriented education. In this sense, OBE education model can be regarded as an innovation of education paradigm.

As a kind of outcome-oriented model, OBE has been mainly considered including the four focuses: what are the learning outcomes that students should achieve? Why should they achieve such learning goals (the formulation of teaching objectives)? How do they achieve these learning outcomes effectively (improvement of teaching contents and the implementation of teaching plans)? How do teachers evaluate these learning achievements (the evaluation of teaching outcomes) [7]? Therefore, students' learning outcome drives the operation of education system.

Since its establishment, OBE has been recognized by education experts at home and abroad for its introduction of new ideas to the reform of traditional classroom teaching, to the cultivation of applied talents, and to the innovation of general education teaching models, whose characteristics can be described as follows:

1) Clear objectives. Educators have a clear expectation of students' performance, and thus the teaching program and schedule are designed around the objectives.

2) Process flexibility. Students can arrange their learning progress in light of their actual states, for educators can give flexible and operable methods in terms of time and standard.

3) Comparability. With the clear objectives, OBE makes students from different regions and schools comparable.

4) Participation. It not only enhances students' initiative to participate in learning, but also arouse the interest of relevant personnel to participate in the formulation and evaluation of education standards [3]. These four points shows that the core idea of OBE education concept is in fact consistent with that of blended learning, that is, students as the center and outcome as the orientation [4]. With OBE approach applied in blended learning, it can not only give full play to the advantages of blended learning, but also change the current phenomenon of overemphasis of theories and neglect of the practice. This new type of blended learning provides new ideas for teaching reform [8].

\subsection{Research Framework}

OBE is a structural model of organizing, implementing and evaluating education with the expected learning outcome as the center. American scholar chandrama Acharya (2003) pointed out that the implementation of OBE approach mainly has four stages: defining, realizing, assessing and using [9]. The defining of learning outcome is to determine the teaching goal, which is both the starting point and the end point of OBE. In order to achieve the goal, it is necessary to 
clearly define the requirements of university undergraduates, that is, to describe the skills, knowledge and ability that the student should achieve in their majors, so as to realize the courses' maneuverability and concretization; The realizing of learning outcome includes the construction of curriculum system and the decision of teaching strategies. Between them, the construction of curriculum system is particularly important for the achievement of learning outcomes for the reason that after its completion, students should have the expected abilities, namely learning outcomes. In the other part-deciding teaching strategies, OBE emphasizes research-based teaching mode and personalized teaching ways, which require teachers to accurately follow students' learning trajectory and make different teaching plans according to different requirements; The assessing of learning outcome means OBE adopts multiple and echelon evaluation to provide a motivator for continuous improvement of the definition of learning outcomes and its realization; Using, as the last step, refers to the process of utilizing learning outcome. The development of this process not only makes the theoretical knowledge in the school applied and tested in practice, but also helps to adjust and improve the new round of training objectives, that is, to redefine learning output.

According to the above four circular processes, this paper follows Acharya's OBE four steps to design the College English blended teaching model (shown in Figure 1): first of all, based on the background of the times and the orientation of the university, it is necessary to determined students' English level after they graduate. Then the graduation requirements of College English are systematically decomposed to form the realizable and valuable parts; secondly, relative educational measures are adopted such as construction of a curriculum system

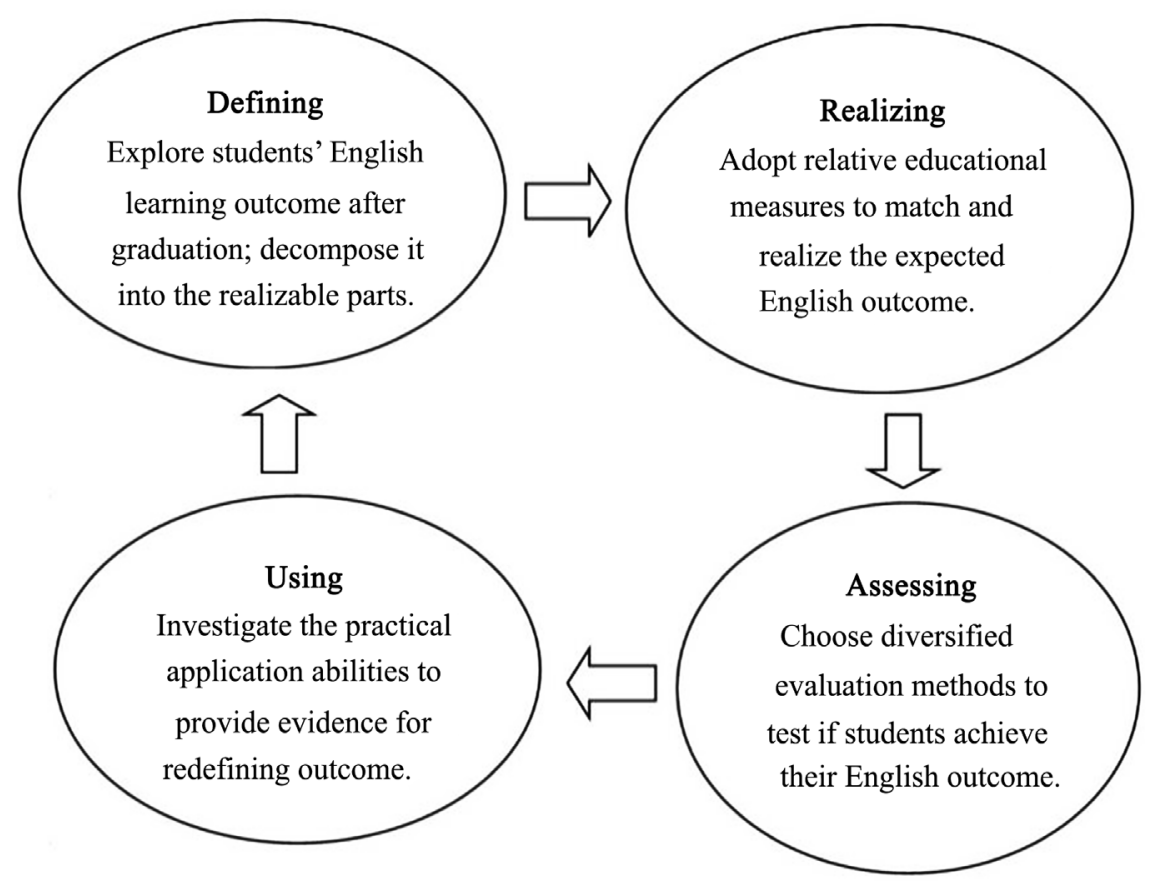

Figure 1. Four-step model of OBE approach. 
and implement of active teaching methods to match the expected educational objectives; thirdly, diversified evaluation methods are adopted to evaluate students' learning effect and teaching quality assurance mechanisms also established, so as to test students' completion of their goals; Finally, investigation of the actual development of students in companies and relevant educational departments provides evidence for the improvement of the teaching quality, which is conducive to adjusting the starting point of defining expected results.

\section{Implementation of Teaching Model}

\subsection{Defining}

The defining of the expected learning outcome of undergraduates is the first step in the development of College English blended teaching mode under OBE approach, for the core of OBE's educational philosophy is to ensure that all students achieve corresponding learning outcomes and acquire the abilities necessary for future success [10]. With the new era that puts forward new demands for talent training, the Core Qualities of Student Development points out the necessary qualities and key abilities that Chinese students should have are that they must meet the needs of social development, although different disciplines and different types of courses have different talent training goals and require learners to have different learning outcomes. Outline of National Medium-and Long-Term Program for Education Reform and Development (2010-2020) proposes to "cultivate a large number of international talents with international vision, who are familiar with international rules, and able to participate in international affairs and international competition". Guidelines on College English Teaching (2020) further points out that the objective of College English is to cultivate students' English language application ability, improve their cross-cultural communication awareness, develop the autonomous learning and critical thinking abilities, so as to meet the needs of the society, colleges and individuals. "As China is a large country with conditions that vary from region to region and from college to college, the teaching of college English should follow the principle of providing different guidance". Based on the national research and data collection, Guidelines on College English Teaching puts forward three levels for requirements for undergraduate college English teaching: basic requirements, intermediate requirements and advanced requirements. Non-English majors are required to attain to one of the three levels of requirements after studying and practicing English at school. However, colleges can make appropriate adjustments according to its status, types and educational goals, to form a dynamic and scientific college English curriculum system that reflects their own characteristics [11].

Therefore, combined with the basic ideas of Guidelines on College English Teaching and the education developmental trend at home and abroad, the expected "learning output" (as shown in Figure 2) of College English can be determined to build a group of international foreign language talents with great 


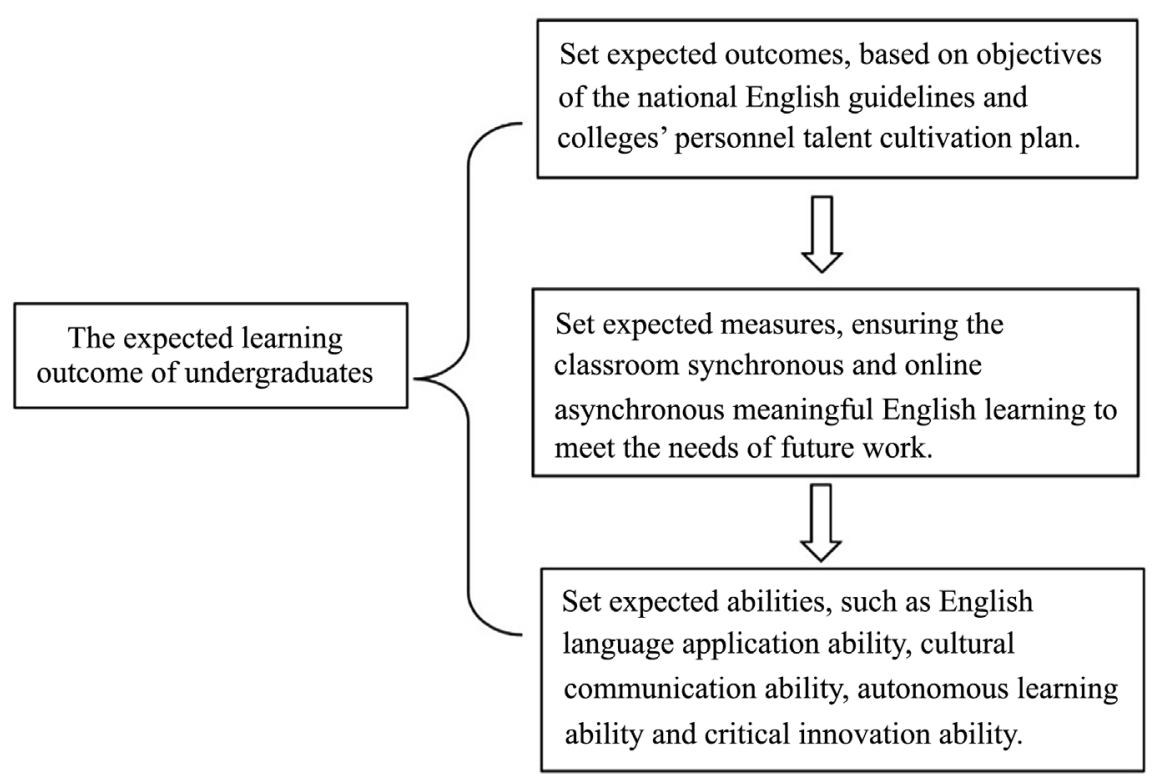

Figure 2. Expected learning outcome of college English.

language skills, extensive knowledge, innovative thinking ability, and active participation in international exchange and cross-cultural communication [12].

\subsection{Realizing}

For more than 200 years, American universities have been exploring the connotation of general education according to the development characteristics of the times. The practice of more than two centuries shows that curriculum is still the main carrier and channel to realize the goal of general education. The research of some domestic experts also shows that the curriculum is of great importance to influence the success of general education [4]. Therefore, as a general education course, the above expected English learning outcome needs to be realized through the implementation of English curriculum.

According to OBE approach that focuses on "what students have learned" rather than "what teachers have taught", English curriculum design centers on the aim of "what students can learn". Therefore, through the definition of the general English learning outcome mention above, the curriculum setup presumes the clarification of the teaching objectives of each chapter, and then follows the arrangement of teaching contents, teaching methods, and teaching evaluation to improve students' English ability. In 2003, Richard M. Felder, an American scholar, puts forward a curriculum design model based on OBE approach: firstly, the teaching objectives of the curriculum are confirmed, to match the national and school education objectives; Secondly, specific teaching content that can achieve the goal need to be designed ; Then, certain teaching methods in the process are considered; Finally, it is necessary to evaluate the course on the learning effect of students, and suggestions are put forward for continuous improvement in teaching objectives [13]. This closed loop of course construction is shown in Figure 3 . 


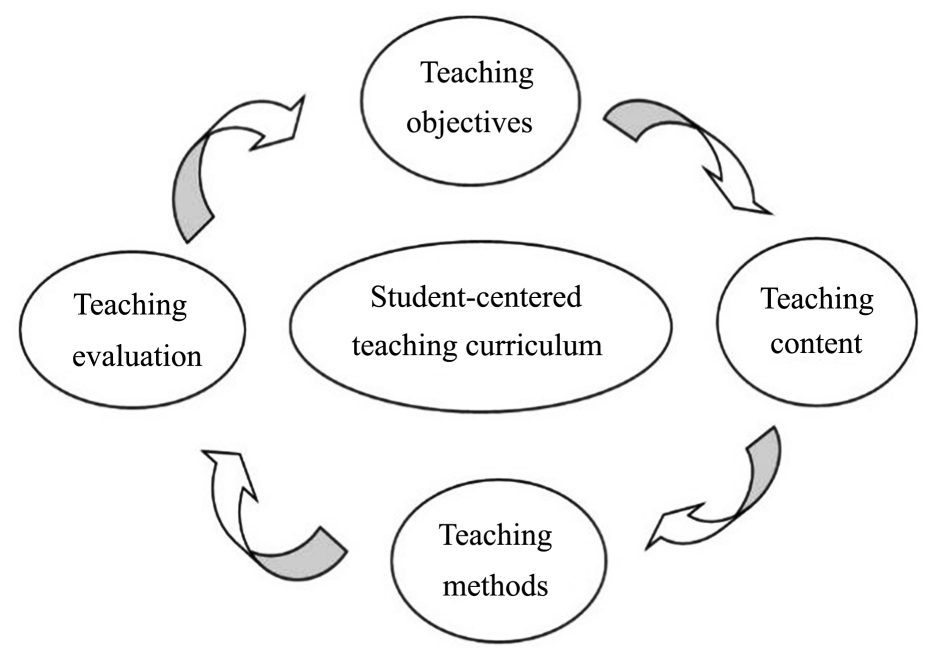

Figure 3. A curriculum design model based on OBE approach.

\subsubsection{Teaching Objectives}

The objectives of curriculum are closely related to the orientation of the general education of the society and the relevant school. College English course, as a non-professional compulsory course to cultivate future international talents, thus has a strong connection to social and cultural characters [9]. According to the expected learning output in Figure 2, students' expected abilities can be divided into four areas: English language application ability, cultural communication ability, autonomous learning ability and critical innovation ability. But teachers need to refine the general goal to decide in details what kind of knowledge and skills to pass on to students. Take unit 1-Self Image from book 4 of New Target College English Integrated Course as an example. Table 2 specifically describes the operational objectives of the blended teaching course: the first level is on English application ability. Through the step, students understand the concept and significance of self-image through the activities of listening, speaking, reading, writing and translation; the second level is on cultural communication ability. The culture and values of self-image from the horizontal and vertical aspects are understood, and the awareness of different cultures enhanced; The third level is on autonomous learning ability, which can stimulate students' interest in learning and mobilize their enthusiasm and initiative by the rich learning resources, methods and evaluation; The fourth level is on critical innovation ability, to cultivate students' critical thinking ability and problem-solving ability through online and offline courses. This kind of comprehensive cultivation of multiple abilities is an integral part of the teaching process and an important concept of OBE. Of course, with the continuous progress of society and the rapid development of globalization, the requirements for international talents and the cultivation of their abilities to solve practical problems endow College English education with the new content to keep pace with the times.

\subsubsection{Teaching Content}

According to the OBE outcome-oriented ideas, the objectives of College English 
Table 2. Blended teaching objectives of unit one.

\begin{tabular}{|c|c|}
\hline \multicolumn{2}{|c|}{ Objectives of Unit One-Self Image } \\
\hline English language application ability & $\begin{array}{l}\text { Listening: understand the corresponding subjects, } \\
\text { the definition and the key points. } \\
\text { Speaking: express views on self-image. } \\
\text { Reading: use reading strategies to master the main idea, } \\
\text { text structure and implied meaning. } \\
\text { Writing: write related papers on the topic. } \\
\text { Translating: use translation skills to analyze long and } \\
\text { difficult sentences in texts. }\end{array}$ \\
\hline Cultural communication ability & $\begin{array}{l}\text { Horizontal aspect: Understand the similarities and } \\
\text { differences in self-image culture and values between } \\
\text { China and foreign countries. } \\
\text { Vertical aspect: compare the changes of self-image } \\
\text { values in different cultures. }\end{array}$ \\
\hline Autonomous learning ability & $\begin{array}{l}\text { Learning resources: use offline resources and } \\
\text { platform resources. } \\
\text { Learning methods: do offline learning } \\
\text { (problem discussion, work evaluation and role play) } \\
\text { and online learning (resource collection, work design, } \\
\text { problem discussion, etc.). } \\
\text { Evaluation method: Evaluate from multi-aspects } \\
\text { including online and offline performance. }\end{array}$ \\
\hline Critical innovation ability & $\begin{array}{l}\text { Judgment: find the prejudice towards self-image } \\
\text { in the society, collect data for analysis and make } \\
\text { explanation and judgment. } \\
\text { Appreciation: analyze the value and significance of } \\
\text { self-image, and cultivate abstract and comprehensive } \\
\text { thinking ability. }\end{array}$ \\
\hline
\end{tabular}

course should be further decomposed so that it can be implemented in each chapter and section that may strengthen students' understanding of language knowledge, and further improve students' foreign language ability [14]. In general, College English contents are classified according to topics. Considering the defined objectives, the process for each topic is usually divided into three important stages: online teaching, face-to-face teaching and online reflection after class.

Online teaching is arranged in the autonomic-learning stage of each new unit, and the contents mainly include the following three points:

1) Students' self-study of the language points in textbooks, online videos or other extended materials on a fixed network platform, in order to lay the knowledge foundation for the later online and offline interactive communication. For example, in the unit of "self-image", some related words such as doll something up, fix oneself up, light up, etc. and some compound words such as self-adaptive, self-perception, self-assured, etc. can help to understand the long and difficult sentences and the main content in the text.

2) Students' conduction of collaborative learning through the way of posting questions in the discussion area, which may include unit discussion around the 
course theme or learning experience sharing, to consolidate their mastery of English expression and improve students' written communication ability. For instance, after the discussion on "how to build self-image" is posted on the platform, students are required to consult the information website, read relevant literature and prepare materials to deepen their understanding of self-image and prepare for the next stage of offline classroom discussion and presentation.

After online learning, face-to-face teaching is generally completed by two roles-teachers as guides and students as participants. Classroom activities in this stage include:

1) Testing students' autonomous learning, which covers answering questions about the text content and summarizing online learning points;

2) Carrying out interactive activities such as topic discussion, which provides students with opportunities to show what they have learned, active their enthusiasm for participation, and better improve their ability of using English language. For example, in the "self-image" discussion, how to define self-image? What is its difference with self-concept and self-identity? What factors make up the way we see ourselves? How does self-image promote or reduce our physical and mental health? How to build a positive self-image? What are the ways to improve it? This process of face-to-face discussion not only guides students' reflection on knowledge and skills, but also leads them to carry out self-reflection and construct self-consciousness.

After the presentation and communication in class, students summarize what they have learned and evaluate the learning process according to the suggestions of teachers and other students. Logging on the network teaching platform, they can submit their learning achievements and reflected summaries to the fixed online area, to achieve the purpose that students can learn from each other, and teachers can evaluate and score them. Therefore, the communication between teachers and students can be extended from inside the classroom to outside the classroom again.

\subsubsection{Teaching Methods}

Generally speaking, teaching method refers to task forms and learning modes that teachers and students use together in order to achieve specific teaching objectives in the teaching process. Under the OBE approach, the college English teaching method is applied in a process in which English teachers guide students to consolidate "old knowledge" and discover "new knowledge" through various enlightening and innovative ways in the pre-class, in-class, and after-class three stages. This two-way interactive process, if carried out smoothly, will promote students' learning efficiency [15], as shown in Figure 4:

1) Pre-class stage

Pre-class learning is mainly completed through micro classes, online tests, network discussion and other teaching methods. In the process of teaching, teachers upload the task and course resources to the network platform according to the course objectives. Faced with the learning difficulties and basic knowledge 


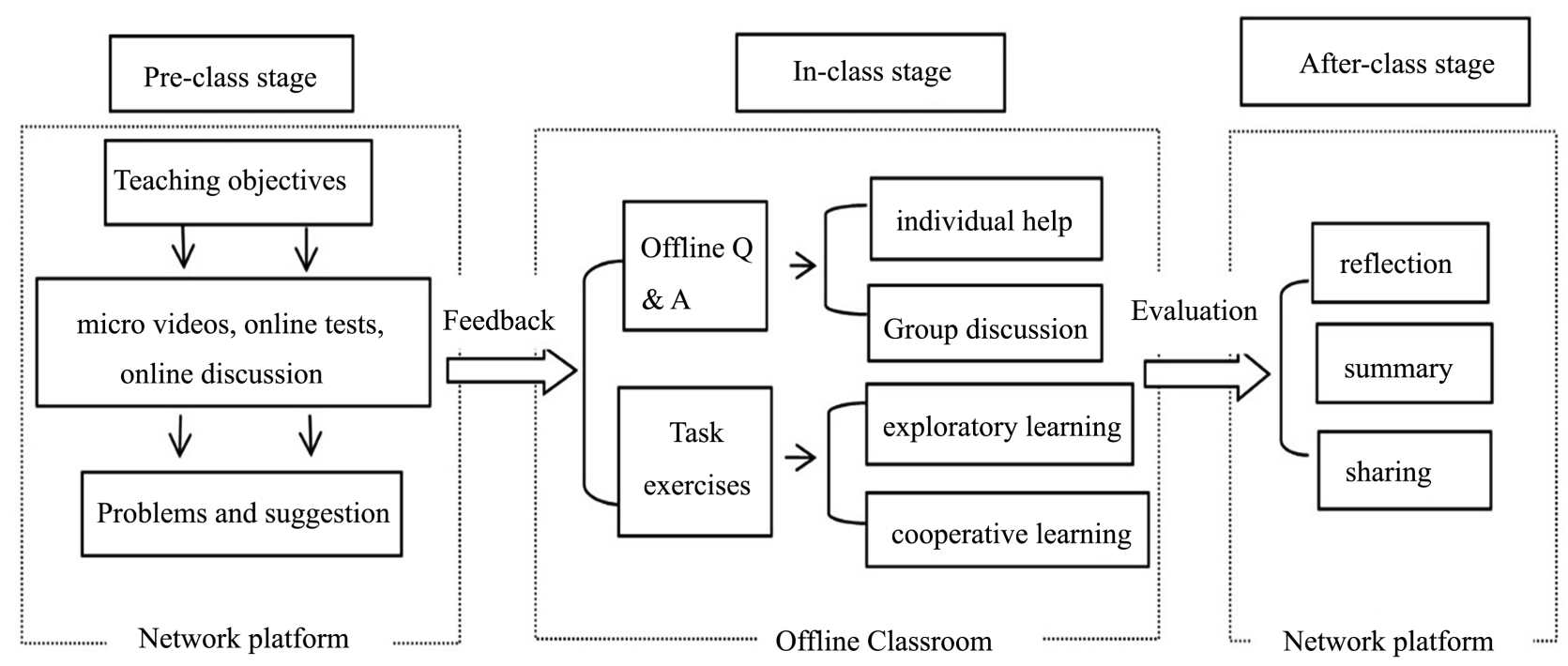

Figure 4. Implementation process of curriculum based on OBE model.

of this unit, students use the relevant resources on the online platform to carry out preliminary preview. In addition to completing related tasks, students will submit relevant questions and suggestions to the learning platform to form pre-class autonomous learning feedback. Meanwhile, teachers use the discussion area, chat room and other network communication tools provided by the platform to conduct synchronous or asynchronous communication with students, with the aim to provide targeted answers and relevant guidance [16].

2) In-class stage

In this stage, with face-to-face instruction, teachers use the method of organized discussion to answer the common problems existing in the process of the first stage and sometimes give individual help to some students. In addition to checking the students' language learning results, the teacher further assists in task exercises in the class, and adopts exploratory or cooperative methods to carry out learning activities. It is worth noting that in the process of instructing students to explore problems on their own, teachers must respect the independence of individual students, thus assisting them in obtaining greater learning efficiency. While in guiding cooperative learning activities, teachers should not only provide support in knowledge and skills to students, but also use various activities such as brainstorming to mobilize students' enthusiasm and initiative in order to ensure the smooth progress of learning activities.

After the exploratory or cooperative learning activities, students can present their learning achievements and share their learning experience through time-limited speeches, debates and other forms. In this process, teachers comment on students' learning achievements, and guide them to summarize and reflect the learning process and construct their learning self-awareness.

3) After-class stage

At this stage, students will submit the final work and summary to the learning platform for a further communication between teachers and students. For one 
thing, teachers can take it as an important part of formative evaluation. For another, they can transform it into reusable and renewable learning resources, so as to promote the education system into a spiral "super cycle" system.

\subsubsection{Teaching Evaluation}

The importance of teaching evaluation lies in the effect of educational activities. A single summative evaluation will make the learning process lack of supervision and incentive, resulting in the accumulation of learning problems, untimely guidance and feedback, and eventually the loss of interest in learning [17]. Therefore, it is necessary to introduce multiple evaluation methods into the blended teaching model, and clarify the contribution of each unit to the realization of the expected learning output of the course [3], which is in line with the core idea of the "outcome-oriented teaching proposition" based on the OBE approach. Specifically, this evaluation method consists of three parts: pre-class evaluation, in-class activity evaluation, and after-class evaluation. It examines students from four levels: language knowledge, communicative competence, autonomous learning, and critical innovation. The whole process is discussed specifically from the following aspects:

1) Online learning evaluation.

It is mainly observed from the students' participation in online learning, discussion, and tests. Dynamic data can be collected from the learning platform, so as to understand the changes and characteristics of learners' behavior. For example, in the pre-class learning evaluation system, teachers usually record login times, video viewing duration and their posting questions to analyze students' initiative in pre-class learning. At the same time, in order to ensure the efficiency of students' autonomous learning, teachers can use the online learning tests provided by the platform to test students' understanding and mastery of knowledge and skills before class. This personalized real-time monitoring and diagnosis are helpful for timely intervention and adjustment to promote the learners' learning efficiency and form good habits.

2) In-class activity evaluation

It mainly checks students' relative knowledge, classroom participation, problem-solving ability and case analysis ability, etc., which is reflected in classroom performance and paper test assessment, combined with multidimensional evaluation from teachers, peers and themselves. For example, in the process of classroom teaching, teachers can set reward points to hold a question and answer session among students, focusing on the assessment of students' problem-solving ability; while in the presentation of collaborative study, mutual evaluation between teachers and students is adopted, focusing on the innovation of students' views, their scientific logic, and their creative way of reporting to put forward suggestions for revision, so as to make a more comprehensive, scientific and effective evaluation of students' development from multiple perspectives.

3) After-class evaluation

After class, students' mastery of knowledge and skill proficiency are usually evaluated through course assessment. Sometimes inter-group evaluation is adopted 
from the perspectives of contents, techniques and creativity after the group collaborative presentations are uploaded to the learning platform. At the same time, in order to motivate each student's sense of team responsibility, peer evaluation is carried out among group members from the aspects of participation, contribution, communicative ability and team cooperative ability, so that learners can find their problems in time and deepen their reflection and improve their abilities in the process of team cooperation.

\subsection{Assessing}

Assessment of learning output is a very important part of OBE approach, but it created a stark fault line for domestic universities. According to the theory and experience of American College Students' learning assessment, the learning output is assessed from three levels-curriculum level, professional level and school level as shown in Figure 5.

At the school level, it can cooperate with relevant educational organizations and institutions that need foreign language talents, to build a practice base for talent training and research for the evaluation of graduation requirements. It is also a good way through the investigations from enterprise employers and the educational departments to investigate whether students' English language abilities meet the job needs, thus to improve the College English teaching quality which is conducive to the realization of higher education accountability [18].

At the professional level, according to the College English teaching objectives and requirements set out in the Guidelines on College English Teaching, the comprehensive test system, including school-based examination, inter-school or regional joint examination, and national unified examination, is adopted to comprehensively test college students' English abilities. This positive guiding role of tests makes it better to provide feedback information to promote the overall improvement of College Students' English ability.
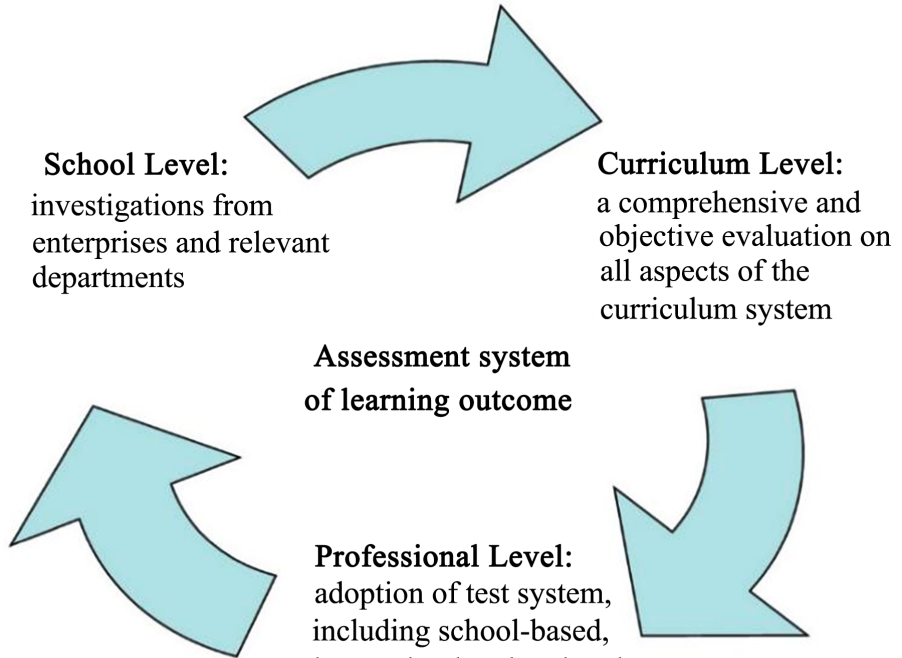

Assessment system of learning outcome

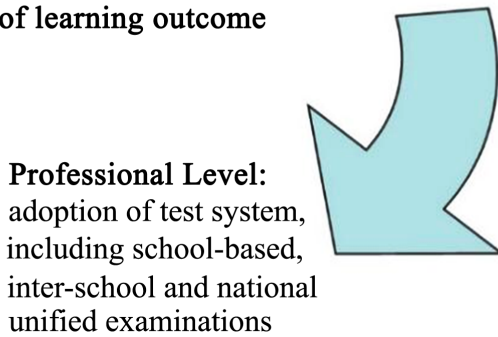

Figure 5. Assessment system of college English learning outcome. 
At the curriculum level, a comprehensive and objective evaluation on all aspects of the curriculum system should be carried out to provide timely and effective feedback for its construction and development of the curriculum. Especially in the aspects of teaching evaluation, it is advisable to adopt diversified evaluation methods such as tests, projects and reports to conduct formative and summative evaluation on students' learning outcome, and from these multiple aspects to investigate whether students have achieved the teaching objectives or not.

\subsection{Using}

Using learning output, as the last stage, refers to the process in which learners make use of learning outcome in their study, work and life. Through the use of learning outcome, theoretical knowledge on books can not only be applied and tested in practice, but also help to adjust and improve classroom teaching and theoretical knowledge learning. At the same time, this kind of test of students' learning effect is helpful to adjust the first stage-defining expected outcomes of students and constantly improving the learning efficiency. Just as Guidelines on College English Teaching says, we should learn from the past successful experience and practice, and pay attention to the latest development of English education theories, to put forward the goals and requirements commensurate with the development of the times, and absorb new ideas, new methods and new achievements in time, to keep pace with the times and adapt to the needs of the new situation of higher education.

\section{Conclusions}

Based on the OBE approach, this research uses reverse design to reform the blended teaching of College English. Composed of four stages, the whole model forms a closed-loop system oriented by learning outcome. This kind of hybrid teaching mode, which combines online and offline teaching and practice contents, realizes more students' sense of participation and experience, which is more conducive to the cultivation of foreign language talents needed by the times.

However, some limitations still exist in this study. First, it is only a theoretical construction of blended teaching model based on OBE. Second, the study has not considered the difficulties during the process such as students' attitudes towards the new learning concept and teachers' abilities to implement the model, which may influence the whole process's controllability.

Therefore, direction for future research is recommended to include a practice application in college English classrooms to test its implementation. In addition, the school needs to make preparation ahead of the process. For example, for teachers, it needs the improvement of their teaching development system as support and corresponding teacher evaluation system as an incentive. For students, it requires their recognition and consciousness towards the new learning con- 
cept with determination and cooperation to adapt to the rapidly changing modern education. These are not only an innovation but also a challenge for both teachers and students. However, the continuous summarization and deepened understanding of the model are hoped to be advantageous for both teachers and students.

\section{Conflicts of Interest}

The author declares no conflicts of interest.

\section{References}

[1] Garrison, D. and Rand Kanuka, H. (2004) Blended Learning: Uncovering Its Transformative Potential in Higher Education. The Internet and Higher Education, 7, 95-105. https://doi.org/10.1016/j.iheduc.2004.02.001

[2] Olakanmi, E.E. (2017) The Effects of a Flipped Classroom Model of Instruction on Students' Performance and Attitudes Towards Chemistry. Journal of Science Education and Technology, 26, 127-137. https://doi.org/10.1007/s10956-016-9657-x

[3] Bai, J., Xie, Y., Li, W. and Wu, L. (2017) A Study on the Structural Model of Open Online Courses Resource Based on OBE Concept in "Internet+" Era. China Educational Technology, 38, 64-69.

[4] Su, P. and Li, M. (2018) The Construction on Curriculum and Teaching in General Education in Tsinghus Case: An Approach of Outcome-Based Education. Research in Higher Education of Engineering, 36, 129-134.

[5] Spady, W.D. (1994) Outcome-Based Education: Critical Issues and Answers. American Association of School Administrators, Arlington.

[6] Tuckers, E. (2004) Literature Review: Outcomes-Focused Education Universities. Learning Support Network, Curtin University of Technology, Bentley.

[7] Li, Q., Cui, J., Yan, Q., Dong, J. and Li, C. (2016) Reform of Practical Teaching Courses for Automation Major under Engineering Education Accreditation. Experimental Technology and Management, 33, 225-228.

[8] Liu, J., Jia, Z. and Shi, J. (2018) Teaching Reform of Blended Course Based on OBE Education Concept: Taking Concrete and Masonry Structure Design Course as an Example. Journal of Architectural Education Institutions of Higher Learning, 27, 87-92.

[9] Acharya, C. (2003) Outcome-Based Education (OBE): A New Paradigm for Learning. Centre for Development of Teaching and Learning, 7, 7-9.

[10] Gu, R., Yang, Q. and Wang, J. (2016) Research on the Reform of OBE Based Secondary Vocational Teacher Training Mode. Adult Education, 36, 65-68.

[11] Ministry of Education of the People's Republic of China (2017) College English Curriculum Requirements. https://www.docin.com/p-2103077956.html

[12] Zhuang, Z., Han, T., Xie, Y., Yan, K. and Liu, H. (2011) On the Cultivation of International Innovative Foreign Language Talents. Foreign Language World, 32, 71-77.

[13] Felder, R.M. and Brent, R. (2003) Designing and Teaching Courses to Satisfy the ABET Engineering Criteria. Journal of Engineering Education, 92, 7-25. https://doi.org/10.1002/j.2168-9830.2003.tb00734.x

[14] Yang, F., Wei, X. and Zhang, W.X. (2017) An Exploration of Blended English Teaching Model. Technology Enhanced Foreign Language Education, 39, 21-28. 
[15] Jia, G. (2016) Teaching Methods, Means and Resources from the Guidelines on College English Teaching. Foreign Language World, 37, 11-18

[16] Wen, X.J. and Liang, Y.Q. (2018) Research on Blending Learning Model from the Angle of the OBE Teaching Philosophy-Based on the Reform of Management Courses. Journal of Higher Education Finance, 20, 45-49+55.

[17] Li, H.J. (2016) Research on the Reform of College English Teaching Mode Based on the Combination of OBE Concept and Flipped Classroom. Journal of Changchun Institute of Technology (Social Science Edition), 17, 132-135.

[18] Gu, P., Hu, W., Lin, P., Bao, N., Lu, X., Xiong, G. and Chen, Y. (2014) OBE Engineering Education Model in Shantou University. Research in Higher Education of Engineering, 32, 27-36. 